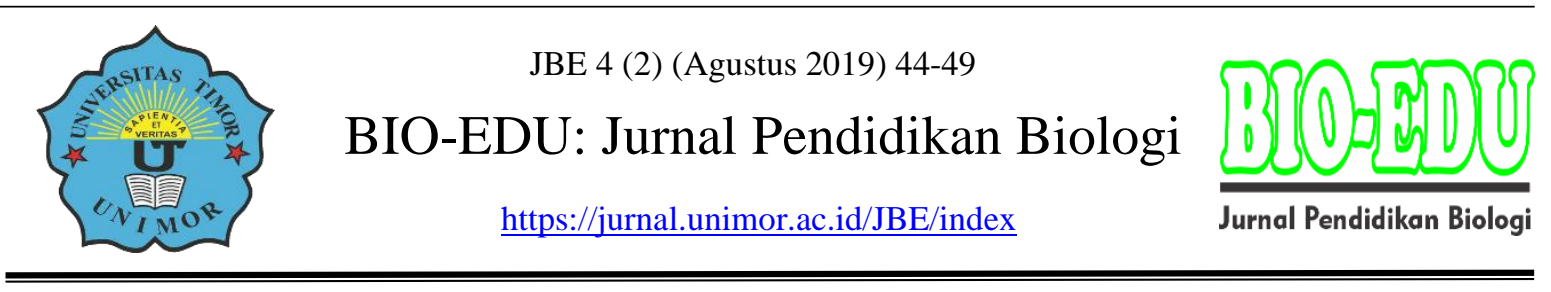

\title{
Intensitas Cahaya dan Efisiensi Fotosintesis Pada Tanaman Naungan dan Tanaman Terpapar Cahaya Langsung
}

\author{
Maria Yustiningsih \\ Program Studi Pendidikan Biologi, Universitas Timor \\ Email: yyustiningsih@gmail.com
}

DOI: https://doi.org/10.32938/jbe.v4i2.385

\begin{abstract}
Abstrak
Pertumbuhan dan produktivitas tanaman dipengaruhi cahaya. Cahaya matahari diperlukan untuk menjalankan reaksi terang (LDR) dan siklus Calvin (LIR). Perubahan intensitas cahaya dapat merubah LDR dan LIR. Penyesuaian diperlukan melalui efisiensi penyerapan foton, pengaturan reaksi fotosistem II dan fotosistem I serta fiksasi karbon agar fotosintesis tetap efisien. Tulisan ini bertujuan mereview penelitian tentang mekanisme fotosintesis pada tanaman naungan dan tanaman terpapar cahaya langsung. Perubahan penyerapan cahaya pada tanaman menghasilkan perubahan morfologi dan fisiologi. Adaptasi pada daun dilakukan melalui sieve effect, light channeling dan aklimatisasi. Perbedaan distribusi klorofil pada kedua jenis tanaman membuat berubahnya photosynthesis photon flux density. Propogasi dan penyaluran cahaya dilakukan melalui vakuola untuk meminimalkan jarak yang harus dilalui oleh electron pada rantai transport elektron. Aklimatisasi fisiologis dilakukan dengan merubah komposisi klorofil dan ratio PSII/PSI. Tumbuhan naungan mempunyai ratio PS II/PSI dan ratio klorofil a/b yang tinggi untuk meningkatkan kompleks pemanen cahaya agar fotosintesis menjadi lebih efisisen.
\end{abstract}

Kata kunci : adaptasi, klorofil, cahaya, fotosintesis, tanaman

\begin{abstract}
Plant growth and productivity influenced by light. Sunlight activate light dependent reactions or LDR and Calvin cycle or LIR in plant. Different light intensity induce change of LDR and LIR. Adaptation through efficiency of photon absorption, regulation of photosystem II - photosystem I, and carbon fixation can make photosynthesis efficiently. This paper aims to review research on photosynthesis mechanism in sun and shade plants. Alteration of light absorption in plants produce morphological and physiological adaptations. Plant adaptation mechanism use sieve effect, light channeling and acclimatization. Distribution of chlorophyll in both types of plants changed the photosynthesis photon flux density. Propogation and distribution of light needed through vacuoles to minimize the distance on electron transport chain. Physiological acclimatization accelerate by changing the composition of chlorophyll and PSII / PSI ratio. Shade plants have a high ratio PS II / PSI and high ratio chlorophyll a / b to increase the light harvesting complex and make photosynthesis efficiently.
\end{abstract}

Keywords: adaptation, chlorophyll, light, photosynthesis, plant

\section{PENDAHULUAN}

Pertumbuhan dan produktivitas tanaman dipengaruhi oleh lingkungan sekitarnya. Cahaya matahari merupakan salah faktor yang mempengaruhi produktivitas tanaman karena 
tidak semua tanaman memerlukan intensitas cahaya yang sama dalam proses fotosintesis. Fotosintesis adalah reaksi penting pada tumbuhan yang berfungsi mengkonversi energi (cahaya) matahari menjadi energi kimia yang disimpan dalam senyawa organic (Campbell \&Reece, 2008). Cahaya matahari diperlukan tanaman sebagai sumber energi untuk menjalankan 2 tahapan reaksi pada fotosintesis yaitu reaksi terang atau light dependent reaction/LDR) yang terjadi di tilakoid dan siklus Calvin atau light independent reaction/LIR) yang terjadi di stroma.

Perubahan intensitas cahaya dapat merubah LDR dan LIR sehingga tanaman perlu melakukan penyesuaian agar proses fotosintesis tetap efisien. Penyesuaian tanaman dalam menghadapi perubahan intensitas cahaya dilakukan antara lain melalui efisiensi penyerapan foton, pengaturan reaksi fotosistem II (PS II) dan fotosistem I (PS I) serta fiksasi karbon (Neri et al, 2003). Diantara ketiga jenis reaksi yang terjadi di dalam kloroplas tersebut, efisiensi penyerapan foton dan pengaturan PS II dan PS I menjadi tahap penting karena penyerapan foton menjadi dasar terbentuknya ATP dan glukosa sebagai produk akhir fotosintesis.

Tulisan ini bertujuan untuk mereview berbagai penelitian yang membahas mengenai mekanisme adaptasi fotosintesis pada tumbuhan yang hidup di bawah naungan (tumbuhan naungan) dan tumbuhan yang terpapar cahaya matahari secara langsung (tumbuhan tahan panas).

\section{HASIL DAN PEMBAHASAN}

\section{Cahaya, Daun dan Fotosintesis}

Cahaya matahari merupakan sumber energi utama bagi reaksi fotosintesis. Energi matahari yang diserap oleh daun sebesar 1- 5\% sedangkan sisanya dikeluarkan melalui transpirasi dan dipancarkan/dipantulkan (Taiz\&Zeiger, 2010). Hasil pemantulan gelombang cahaya ke udara ini menghasilkan warna vegetasi alami yang diterima oleh mata.

Efisiensi penyerapan cahaya oleh daun dapat menghasilkan perubahan morfologi dan fisiologi yang berbeda. Penelitian yang dilakukan pada tanaman kopi menunjukkan bahwa laju fotosintesis pada kopi sangat dipengaruhi bentuk hidrolic daun yang berpengaruh pada stomata konduktan (gs) (Martins et al, 2014). Kopi merupakan jenis tanaman yang tumbuh dibawah naungan sehingga penyerapan intensitas cahaya tidak maksimal. Martin et al (2014) melakukan penelitian pengukuran laju fotosisntesis (A) pada tanaman kopi terkena cahaya langsung dan kopi tumbuh di bawah naungan. Hasil menunjukkan laju fotosintesis pada kopi yang terkena cahaya langsung tetap rendah dikarenakan adanya mekanisme resistensi difusi $\mathrm{CO}_{2}$ yang rendah dan laju fotorespirasi yang tinggi. Kemampuan fiksasi $\mathrm{CO}_{2}$ yang rendah akan berpengaruh pada kinerja enzim Rubisco, dimana tumbuhan tidak akan membuang energi untuk membentuk Rubisco dalam jumlah besar jika $\mathrm{CO}_{2}$ yang difiksasi sedikit; sehingga proses reaksi pembentukan Rubisco melalui transport electron akan disesuaikan. Energi dari transport electron bermula dari penyerapan foton yang diterima oleh daun melalui reaksi PS II dan PS I.

Penyesuaian serapan foton akan berakibat pada penyesuaian serapan cahaya yang dibutuhkan oleh daun. Menurut Taiz\&Zeiger (2010) factor yang dapat mempengaruhi laju fotosintesis adalah aktivitas Rubisco, regenerasi ribulose bisphosphate (RuBP) dan 
metabolisme gliseral dehide 3 fosfat (G3P). Aktivitas rubisco dan RuBP sangat dipengaruhi oleh intensitas cahaya sedangkan metabolisme G3P ditentukan oleh fiksasi $\mathrm{CO}_{2}$.

\section{Mekanisme adaptasi daun terhadap cahaya}

Struktur anatomi dan morfologi daun merupakan salah satu mekanisme adaptasi yang dilakukan tumbuhan terhadap intensitas cahaya yang berbeda (Peri et al, 2009). Tujuannya adalah agar tumbuhan mampu melakukan penyerapan cahaya optimal dan melakukan proses fotosintesis secara efisien. Jenis adaptasi yang dilakukan oleh tumbuhan dapat berupa sieve effect atau efek penyaringan, light channeling atau penyaluran cahaya, dan aklimatisasi (Taiz\&Zeiger, 2010).

Sieve effect

Distribusi klorofil yang tidak merata pada semua sel tumbuhan dan hanya berkonsentrasi pada kloroplas dapat menghasilkan efek penyaringan yang efektif. Pada tanaman yang tumbuh di daerah naungan dan dibawah kanopi akan membungkus klorofil (klorofil packaging) dengan memberikan jarak yang lebih lebar di stroma daripada tanaman yang terpapar cahaya langsung (Taiz\&Zeiger, 2010). Efek penyaringan akan menghasilkan total penyerapan cahaya lebih sedikit bila dibandingkan dengan jumlah total klorofil.

Pada daerah kanopi penyerapan cahaya dapat berlangsung efisien karena adanya keseimbangan penyerapan $\mathrm{CO}_{2}$ yang terbatas. Lewis et al (2000) menyatakan bahwa terjadi penurunan penyerapan foton atau photosynthesis photon flux density (PPFD) secara gradient pada kanopi hutan hujan. Menurut Lewis, hutan hujan merupakan salah satu jenis hutan penting untuk diteliti karena potensial carbon yang dapat diserap dan banyaknya pola vegetasi yang terbentuk dibawahnya. Perbedaan yang terbentuk pada hutan hujan disebabkan lapisan kanopi bagian atas menerima cahaya lebih banyak sehingga akan menyerap $\mathrm{CO}_{2}$ lebih tinggi bila dibandingkan dengan lapisan dibawahnya (gambar 1).

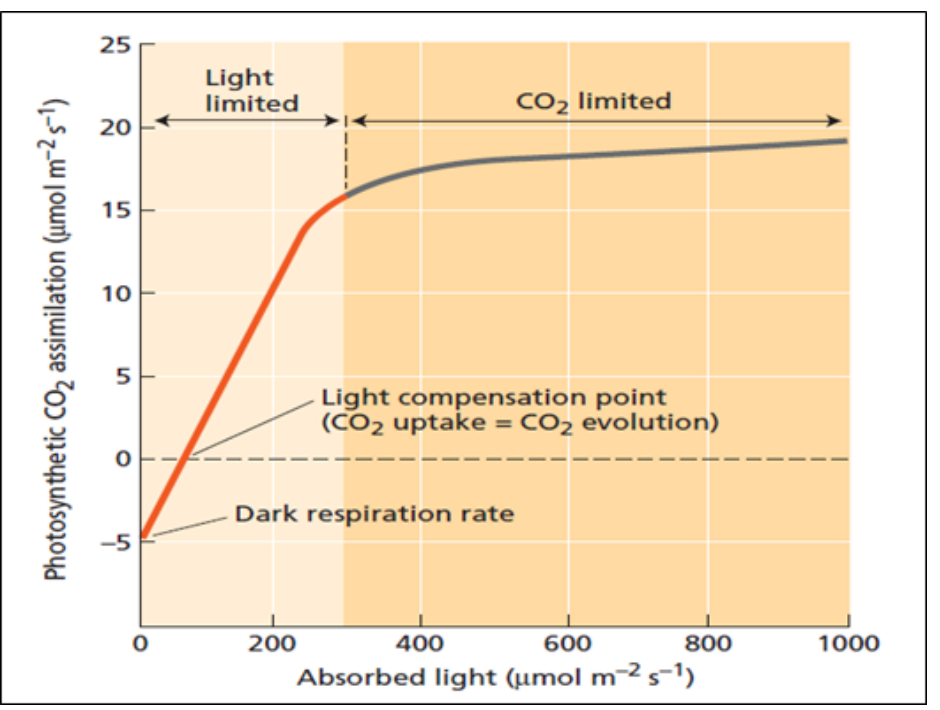

Gambar 1. Respon fotosintesis terhadap cahaya pada tanaman naungan. Pada kondisi cahaya terbatas respirasi menyebabkan terjadinya aliran $\mathrm{CO2}$ dari tanaman Sumber : Taiz\&Zeiger (2010) 


\section{Light chanelling dan light scattering}

Ketika intensitas cahaya yang diserap oleh kanopi rendah, maka potensial elektron yang tereksitasi menjadi rendah karena energi foton yang terbatas. Tumbuhan membuat strategi penyaluran dan pendistribusian cahaya secara efisien yaitu dengan mempendarkan dan menyalurkan cahaya. Propogasi cahaya dilakukan melalui vakuola dan permukaan sel yang berongga untuk memaksimalkan energi dan meminimalkan jarak yang harus dilalui oleh electron pada rangkaian transport electron. Semakin besar jarak yang harus dilalui oleh electron maka semakin besar energi yang diperlukan (Martins et al, 2014). Oleh karenanya kedua jenis tumbuhan mempunyai laju fotosintesis (A) yang berbeda. Gambar 2 menunjukkan penyerapan cahaya dan penyerapan $\mathrm{CO} 2$ yang berbeda antara tanaman naungan (Asarum caudatum) dan tanaman tahan panas (Atriplex triangularis) yang menyebabkan perbedaan laju A.

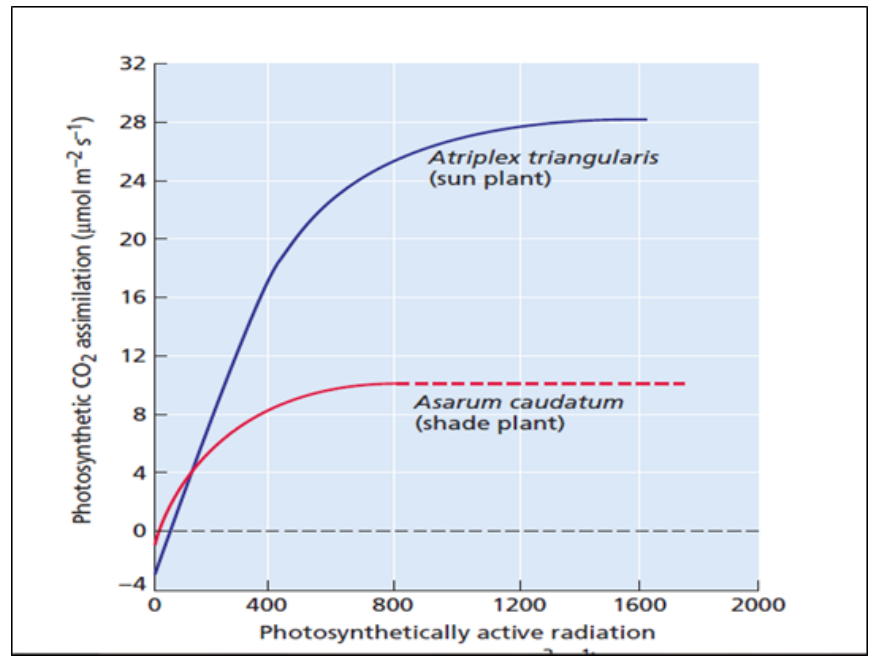

Gambar 2. Grafik respon cahaya dan fiksasi CO2 pada tanaman naungan dan tanaman terpapar cahaya secara langsung Sumber : Taiz\&Zeiger (2010)

\section{Aklimatisasi}

Tumbuhan yang telah mampu beradaptasi dengan lingkungan akan menghasilkan struktur, morfologi dan fisiologi yang sesuai dengan lingkungan. Adaptasi memungkinan tumbuhan mengembangkan organ khusus dan terspesifikasi menghadapi intensitas cahaya yang berbeda. Pulvinus - terletak antara petiole dan tangkai - merupakan salah satu organ pengatur dan dapat menggerakkan daun mengikuti arah cahaya. Berdasarkan arah orientasi cahaya tumbuhan dapat bersifat heliotropism yaitu tumbuhan dengan daun yang mengarah ke cahaya, merupakan jenis tumbuhan di bagian atas kanopi; paraheliotropism adalah tumbuhan dengan daun yang menghindari cahaya, merupakan jenis tumbuhan di bawah kanopi; dan diaheliotropism yaitu tumbuhan dengan daun yang mampu memaksimalkan absorpsi cahaya minimal untuk proses fotosintesis yang efisien.

Proses aklimatisasi secara fisiologis dilakukan oleh tumbuhan diaheliotropism dan paraheliotorpism melalui perubahan komposisi jumlah klorofil total dan ratio PSII/PS I. Pada naungan atau tumbuhan yang tidak terkena cahaya matahari secara langsung mempunyai klorofil total yang tinggi dan dengan ratio PS II : PS I = $3: 1$. Sedangkan pada tumbuhan 
yang terpapar matahari secara langsung ratio PS II : PS I = $2: 1$ dengan kandungan rubisco yang lebih tinggi. Kondisi ternaungi atau cahaya tidak langsung akan mendorong penyerapan spectrum cahaya merah jauh lebih tinggi sehingga akan mendorong produksi klorofil a (Salisbury and Ross, 1992). Kandungan klorofil b merupakan parameter yang menunjukkan kandungan klorofil yang berpengaruh pada proses metabolisme namun sintesisnya dipengaruhi oleh klorofil a. Atwell et al (1999) dan Pearcy (1999) menyebutkan bahwa tingginya ratio klorofil a/b merupakan refleksi dari peningkatan kompleks pemanen cahaya (LHCII) relative terhadap pusat reaksi. Peningkatan ini akan mempertinggi efisiensi pemanenan cahaya (Khumaida et al., 2003), sehingga dengan sumber cahaya terbatas tanaman tetap dapat melakukan proses fotosintesis yang efisien.

\section{KESIMPULAN}

Intensitas cahaya sangat berpengaruh terhadap efisiensi fotosintesis suatu tanaman. Penyesuaian tanaman naungan dan tanaman tahan panas terhadap intensitas cahaya menghasilkan proses fotosintesis yang efisien sehingga kedua jenis tumbuhan dapat tetap hidup dan mempunyai produktivitas yang tinggi.

\section{DAFTAR RUJUKAN}

Adams W.W., Todd Rosentiel., Barbara Demmig - Adams., Volker Ebbet (2001). Dependence of photosynthesis and energy dissipation activity upon growth form and light environment during the winter. Photosynthesis Research,67 (1-2), 51 - 62.

Davide Neri., Roberto Batistelli and Gianni Albertini (2003). Effect of Low Light Intensity and Temperature on Photosynthesis and Transpiration of Vigna sinensis L. Journal of Fruit and Ornamental Plan Research, 11, 17 - 24.

Gross Luis (1982). Photosynthetic Dynamic in Varying Light Environments: A Model And Its Application To Whole Leaf Carbon Gain Department of Mathematics and Program in Ecology, University of Tennessee, Knoxville, Tennessee.

Lewis.J.D., McKane.R.B., Tingey.D.T., and Beedlow. P.A (2000). Vertical gradients in photosynthetic light response within an old-growth Douglas-fir and western hemlock canopy. Jurnal Tree Physiology Heron Publishing —Victoria, Canada, 20, 447 - 456.

P.L.Peri., G.Martines Pastur., M.V. Lencinas (2009). Photosynthetic response to different light intensities and water status of two main Nothofagus species of southern Patagonian forest, Argentina. Journal of Forest Science, 55 (3), 101 - 111.

Samuel C.V Martins., Jeroni Galmes., Paulo C.Cavatte.,Lucas F.Pareira., Marilia C. Ventrella and Fabio M. DaMatta (2014). Understanding the Low Photosynthetic Rates of Sun and Shade Coffee Leaves: Bridging the Gap on the Relative Roles of Hydraulic, Diffusive and Biochemical Constraints to Photosynthesis. Jurnal Plos One, 9 (4), 1 - 10.

Lincoln Taiz., Eduardo Zeiger (2010). Plant Physiology $5^{\text {th }}$ edition: Physiological and Ecological Considerations, Chapter 9. Sianuer Associates Inc, Publisher Sunderland, Massachusetts, USA.

48|Yustiningsih/JBE 4(2) (Agustus 2019) 44-49 
Thompson W.A., Huang L.K., Kriedemann P.E (1992). Photosynthetic Response to Light and Nutrients in Sun-Tolerant and Shade-Tolerant Rainforest Trees. II. Leaf Gas Exchange and Component Processes of Photosynthesis. Australian Journal of Plant Physiology, 19 (1), $19-42$. 